other measurements of body composition will further elucidate the relationship between body size and kidney cancer.

\section{5-6.6 INFERTILITY AND MEDITERRANEAN DIETARY PATTERN: A NESTED CASE-CONTROL STUDY}

doi:10.1136/jech.2011.142976b.69

E Toledo,* C Lopez-del Burgo, T Errasti-Alcalá, M Bes-Rastrollo, J J Beunza, M Á Martínez-González, J de Irala. University of Navarra, Pamplona, Navarra, Spain

Introduction Infertility affects approximately 15\% of couples during their reproductive lifetime. We aimed to investigate associations between different dietary patterns (DP) and difficulty for getting pregnant in the SUN Project.

Methods Using data from the SUN (Seguimiento Universidad de Navarra) dynamic prospective cohort of university graduates, we conducted a nested case-control analysis of 485 cases and 1670 controls aged $20-45$ years. Cases were female participants who referred having consulted a doctor due to difficulties for getting pregnant. Controls were female participants not having consulted for this reason and having at least one child. Cases and controls were matched according to age. We performed principal component analyses with orthogonal varimax rotation to determine the main DPs in our cohort. We divided our sample according to quartiles of the empirically-identified DPs and conducted conditional logistic regression models.

Results Out of 9811 women enrolled with $20-45$ years of age, 485 referred having consulted a doctor due to difficulty to getting pregnant. Two main DPs were identified: a Western DP and a Mediterranean-type DP. Once potential confounders were adjusted for, no significant association was observed for a higher adherence to the Western DP (OR 1.09 (95\% CI 0.75 to 1.57)). After adjusting for potential confounders, women with a higher adherence to the Mediterranean-type DP had a lower risk for consulting for difficulty to getting pregnant (OR 0.62 (95\%: 0.39 to 0.99 )).
Conclusion Our data suggest that a higher adherence to the Mediterranean-type DP might have a protective effect on infertility.

\section{Wednesday 10 August 2011 \\ Parallel session 6 \\ 6.1 THE GLOBAL STATUS OF EPIDEMIOLOGY}

\section{Chair: Prof Cesar Victora, Brazil 06-1.1 The GLOBAL STATUS OF EPIDEMIOLOGY}

doi:10.1136/jech.2011.142976b.70

\begin{abstract}
${ }^{1}$ A Mandil, ${ }^{*}$ E Franco, ${ }^{*} \mathrm{~S}$ Barreto, ${ }^{*}$ D Prabhakaran, ${ }^{*} \mathrm{~T}$ Blakely, ${ }^{*}{ }^{6} \mathrm{~J}$ Nachega. ${ }^{*}$ ${ }^{1}$ King Saud University, Saudi Arabia; ${ }^{2}$ Mc Gill University, Canada; ${ }^{3}$ Universidade Federal de Minas Gerais, Brazil; ${ }^{4}$ Centre for Chronic Disease Control, India; ${ }^{5}$ University of Otago, New Zealand; ${ }^{6}$ Stellenbosch University, South Africa
\end{abstract}

To take stock of the current status of epidemiology throughout the world, the International Epidemiological Association commissioned a series of eight reviews that are being published in the International Journal of Epidemiology, starting in February 2011. Each review addresses one region of the world, and starts by describing the burden of disease and the current status of epidemiology, covering human resources, training, academic and research institutions, publication patterns, epidemiologic surveillance institutions, and epidemiologic societies. The reviewers then outline the main future challenges for the development of epidemiologic capacity in their regions. The session will include short presentations by the lead writers from the Western Pacific, Middle-East and North Africa, Latin American and Caribbean, North American, South Asia, SubSaharan Africa regions, followed by a general discussion on the similarities and differences among regions. 